\title{
Silica nanoparticles induce cardiomyocyte apoptosis via the mitochondrial pathway in rats following intratracheal instillation
}

\author{
ZHONGJUN DU $^{1 *}$, SHANGYA CHEN $^{1 *}$, GUANQUN CUI $^{2 *}$, YE YANG $^{1}$, ENGUO ZHANG $^{1}$, \\ QIANG WANG ${ }^{3}$, MARTIN F. LAVIN ${ }^{1,4}$, ABREY J. YEO ${ }^{1,4}$, CUNXIANG BO $^{1}$, YU ZHANG ${ }^{1}$, \\ CHAO LI ${ }^{1}$, XIAOSHAN LIU ${ }^{5}$, XU YANG ${ }^{1}$, CHENG PENG $^{1,6}$ and HUA SHAO ${ }^{1}$
}

${ }^{1}$ Department of Toxicology, Shandong Academy of Occupational Health and Occupational Medicine, Shandong Academy of Medical Sciences, Ji'nan, Shandong 250062; ${ }^{2}$ Department of Respiratory Medicine, Qilu Children's Hospital of Shandong University, Ji'nan, Shandong 250012; ${ }^{3}$ Department of Preventive Medicine and Public Health Laboratory Science, School of Medicine, Jiangsu University, Zhenjiang, Jiangsu 212013, P.R. China; ${ }^{4}$ Univeristy of Queensland Centre for Clinical Research (UQCCR), The University of Queensland, Brisbane, QLD 4102, Australia; ${ }^{5}$ Department of Radiology, Shandong Tumor Hospital, Shandong Academy of Medical Sciences, Ji'nan, Shandong 250117, P.R. China; ${ }^{6}$ Queensland Alliance for Environmental Health Sciences (QAEHS),

The University of Queensland, Brisbane, QLD 4102, Australia

Received July 3, 2018; Accepted December 18, 2018

DOI: 10.3892/ijmm.2018.4045

\begin{abstract}
Diseases of the cardiac system caused by silicon dioxide exposure have captured wide public attention. Upon entering the blood circulation, ultrafine particles have the potential to influence cardiomyocytes, leading to myocardial ischemia or even cardiac failure, and the molecular mechanisms remain to be completely elucidated. In this study, the toxicity of ultrafine particles on cardiomyocytes from rats exposed to silica nanoparticles was observed. Rats were randomly divided into a normal saline control group and three exposure groups $(2,5$ and $10 \mathrm{mg} / \mathrm{kg}$.body weight) that were intratracheally treated with $60-\mathrm{nm}$ silica nanoparticles. Alterations in body weight, routine blood factors and myocardial enzymes, histopathological and
\end{abstract}

Correspondence to: Dr Cheng Peng or Professor Hua Shao, Department of Toxicology, Shandong Academy of Occupational Health and Occupational Medicine, Shandong Academy of Medical Sciences, 18877 Jingshi Road, Lixia, Ji'nan, Shandong 250062, P.R. China

E-mail: c.peng@uq.edu.au

E-mail: chinashaohua5888@163.com

${ }^{*}$ Contributed equally

Abbreviations: TEM, transmission electron microscopy; LAL, limulus amoebocyte lysate; CK-MB, creatine kinase-MB; LDH, Lactate dehydrogenase; WBC, white blood cells; RBC, red blood cells; PLT, platelets; HGB, hemoglobin; TUNEL, terminal deoxynucleotidyl-transferase-mediated dUTP nick end labelling; Cyt C, cytochrome C

Key words: silica nanoparticles, cardiac toxicity, apoptosis, rats microstructural alterations, apoptosis and the expression of apoptosis-associated proteins were assessed at the end of the exposure period. The silicon levels in the heart and serum, and myocardial enzymes in exposed rats were significantly increased in a dose-dependent manner. In addition, exposure to the silica nanoparticles caused notable histological and ultrastructural alterations in the hearts of these animals. Furthermore, a significant apoptotic effect was observed in the exposure groups. The present data suggest that silica nanoparticles may enter the circulatory system through the lungs, and are distributed to the heart causing cardiovascular injury. Silica nanoparticle-induced apoptosis via the mitochondrial pathway may serve an important role in observed cardiac damage.

\section{Introduction}

Silica nanoparticles are one of the most important nanomaterials. Due to their small particle size $(<100 \mathrm{~nm})$, large specific surface area, good dispersibility and high chemical purity, silica nanoparticles are widely used in the fields of material science, cosmetics and biomedicine $(1,2)$. Due to this, silica nanoparticles may be found in a variety of occupational environments $(3,4)$. Exposure to silica nanoparticles may occur through inhalation, ingestion, transdermally and by permeation (5). It has been reported that inhalation is the principal route of nanoparticle exposure, and inhaled particles may be transferred into the circulatory system through the blood-air barrier (6). It has also been reported that inhaled superfine particles may be transferred to the bone marrow, heart and liver $(7,8)$.

Physical and chemical properties may affect the biological impact of nanomaterials. Certain metal nanoparticles are able to release their metal ions through biological metabolism, which leads to more serious damage to the body (9). 
Considering the high stability of silica, its biological toxicity is likely associated with its physical properties (e.g., diameter, quantity and superficial area) and surface modification. Compared with conventional-sized particles, nanoparticles are more likely to penetrate into the lungs through inhalation. As such, they are able to effectively avoid pulmonary clearance (10). Importantly nanoparticles are able to directly penetrate into cells, where they interact with the intracellular macromolecules and cause structural damage $(11,12)$. It has been confirmed that at a constant diameter, the cytotoxicity of silicon $(\mathrm{Si})$ nanotubes increases as their length decreases $(13,14)$. A study of liver damage in mice induced by unmodified silica nanoparticles $(70 \mathrm{~nm})$ identified that compared with unmodified silica nanoparticles, the decrease in liver damage associated with surface modification was attributed to a decrease in cytotoxicity to parenchymal hepatocytes (15).

Diseases of the respiratory system caused by silicon dioxide exposure have drawn broad public attention; however, cardiovascular injury and other diseases due to exposure to silica nanoparticles are not widely understood. Few studies have demonstrated a correlation between cardiac effects and silica nanoparticle exposure. A study using a zebrafish model indicated that cardiac dysfunction was induced by low-dose $60 \mathrm{~nm}$ silica particles via neutrophil-mediated cardiac inflammation and calcium signaling pathways associated with gene-mediated cardiac contraction (16). In addition, the combined toxicity of methylmercury and silica nanoparticles is greater than that of single exposure (17). Exposure of rat cardiomyocytes to $7 \mathrm{~nm}$ or $670 \mathrm{~nm}$ silica nanoparticles demonstrated that the particles cause cardiotoxicity by reducing sarcoplasmic reticulum $\mathrm{Ca}^{2+}$-ATPase activity, limiting calcium release, reducing cell shortening, depolarizing the mitochondrial membrane potential and enhancing oxidative stress, affecting mitochondrial function (18). While in vivo experiments have demonstrated that the cardiovascular toxicity of $60 \mathrm{~nm}$ silica particles primarily results from activated endothelial cell autophagic activity and mitochondrial damage, the mechanism may be associated with angiogenesis and the vascular endothelial growth factor receptor 2-mediated autophagy signaling pathway (19).

Inhaled nanoparticles may be transported to the extrapulmonary tissue through multiple mechanisms upon reaching the pulmonary interstitium, where they rapidly enter the blood circulation and are distributed to the whole body (20-23). Particles distributed in the heart and vessels may cause damage to the cardiovascular system. Studies have confirmed that cardiomyocyte injury caused by atmospheric particulate matter principally includes myocardial ischemia, apoptosis and necrosis (24-26). Following apoptosis, the tissue is remodeled through cell proliferation and the level of remodeling is associated with the homeostasis of apoptosis and proliferation (27). Apoptosis regulator BAX (Bax), apoptosis regulator Bcl-2 (Bcl-2) and caspases, particularly caspase-3, are key execution enzymes in mitochondria-mediated apoptosis (28). Varieties of nanomaterials have been demonstrated to cause the occurrence of cellular apoptosis. It has been reported that nanosilver induces apoptosis of NIH3T3 cells through the translocation of cytochrome $\mathrm{C}(\mathrm{Cyt} \mathrm{C})$ into the cytoplasm and Bax into the mitochondria (5). A study also demonstrated that titanium dioxide nanoparticles induce apoptosis in MC3T3-E1 cells (29), and single-walled carbon nanotubes also induce apoptosis (30). Nanoparticles metal oxides have been demonstrated to induce teratogenic effects in zebrafish toxicity experiments, including serious cardiac edema and yolk sac edema (31). The initiation of cellular apoptosis is considered to be of the primary mechanisms of cytotoxicity induced by nanomaterials (7).

The molecular mechanism of cardiovascular damage caused by inhalable ultrafine particles is not fully understood. It has been proposed that ultrafine particles are most likely to influence cardiac function by causing apoptosis-associated mitochondrial dysfunction (32). The aim of the present study was to investigate whether silica nanoparticles are able to induce myocardial cytotoxicity through the mitochondrial apoptosis pathway after entering the blood circulation. Therefore, it was hypothesized that amorphous silica nanoparticles may induce cardiomyocyte apoptosis in rats following intratracheal instillation. It was further hypothesized that the cardiomyocyte apoptosis induced by amorphous silica nanoparticles may be mediated through regulation of the mitochondrial apoptosis pathway-associated proteins Bax, Bcl-2, and caspase-3. To test this hypothesis, male Wistar rats were exposed to amorphous silica nanoparticles by intratracheal instillation every other day for a total of 15 treatments, to evaluate cardiomyocyte apoptosis and histopathological alterations, and to measure the expression of proteins involved in the mitochondria-associated apoptotic pathway.

\section{Materials and methods}

Characterization of silica nanoparticles. Silica nanoparticles of $60 \mathrm{~nm}$ in aqueous suspension were obtained from the School of Chemistry, Jilin University (Changchun, China). Silica nanoparticle sizes and distributions were measured by transmission electron microscopy (TEM; JEOL, Ltd., Tokyo, Japan). The hydrodynamic sizes of silica particles in dispersion medium were examined by $\zeta$-electric potential granulometry (Nano ZS90; Malvern Panalytical, Ltd., Malvern, UK) using dynamic light scattering. The crystal structure of the particles was characterized using a Scintag XDS 2000 diffractometer (Scintag, Inc., Cupertino, CA, USA) and endotoxin levels of the silica nanoparticle solutions of $60 \mathrm{~nm}$ were determined in a limulus amebocyte lysate (LAL) assay, as described previously (33).

Experimental animals. Male Wistar rats weighing $200 \mathrm{~g}$ (8 weeks old) were obtained from the Department of Experimental Animals, Norman Bethune College of Medicine, Jilin University (Changchun, China) [animal certificate no. SYXK (Ji) 2007-0011]. Animals were bred under specific pathogen-free conditions (temperature, $20-24^{\circ} \mathrm{C}$; humidity, 45-60\%; light/dark cycle, $12 \mathrm{~h} / 12 \mathrm{~h}$ ) and kept in specific pathogen-free conditions during the experiment. Food and water were provided ad libitum. All animals were treated according to the experimental protocols and procedures evaluated and approved by the ethical committee of Norman Bethune College of Medicine, Jilin University. 
Experimental design. The procedures for silica nanoparticle exposure were based on a previous study (33). Briefly, 40 male Wistar rats were randomly divided into four groups with 10 rats/group. Rats in the control group were treated with $0.9 \%$ physiological saline for comparison. The three experimental groups received silica nanoparticles at 2, 5 and $10 \mathrm{mg} / \mathrm{kg}$ body weight (bw), respectively. According to the World Health Organization (WHO) standards and adult rat physiology, the daily inhaled particulate matter of the adult rats was $2.63 \mu \mathrm{g}$, or $13.15 \mu \mathrm{g} / \mathrm{kg} \cdot \mathrm{bw}$. Extrapolating to humans, it was determined that the concentration of silica nanoparticles was 2,5 and $10 \mathrm{mg} / \mathrm{kg} \cdot \mathrm{bw}$, representing 100,250 and 500 times the average concentration of that used for PM2.5 in WHO air quality standards, according to the safety factors for toxicity experiments. Silica nanoparticle suspension was delivered into the rat lung by intratracheal instillation under ether anesthesia every other day for a total of 15 treatments. Subsequent to the experiments, the rats were weighed, and blood was collected. Hearts were weighed and tissue samples were homogenized and frozen to analyze the silica content. The concentrations of $\mathrm{Si}$ in the heart and serum were determined by inductively coupled plasma atomic emission spectrometry (PerkinElmer, Inc., Waltham, MA, USA) as described previously (33).

Blood biochemical analyses. Levels of creatine kinase-MB isoenzyme (CK-MB) were measured by ELISA (cat. no. S032; Groundwork Biotechnology Diagnosticate, Ltd., San Diego, CA, USA), according to the manufacturer's protocol, measuring the absorbance at $450 \mathrm{~nm}$ using a Synergy 2 multi-mode microplate reader (BioTek Instruments, Inc., Winooski, VT, USA). Lactate dehydrogenase (LDH) was measured using a commercial kit (cat. no. A125; Nanjing Jiancheng Bioengineering Institute, Nanjing, China), according to the manufacturer's protocol, using a UV-752 Spectrophotometer (Shanghai Lengguang Technology Co., Ltd., Shanghai, China). Blood samples were analyzed for the quantity of white blood cells (WBC), red blood cells (RBC) and platelets (PLT), and the concentration of hemoglobin (HGB), using an automated hematological analyzer (model no. KX-21NV; Sysmex Corporation, Kobe, Japan).

Histopathological examination. Heart tissues were processed for histopathological evaluation using standard laboratory procedures, as previously described (34). Briefly, the left lung was removed using a razor blade and fixed with $10 \%$ formaldehyde solution. The tissues were embedded in paraffin blocks and sliced to $5 \mu \mathrm{m}$ slices, and mounted onto slides. Following hematoxylin-eosin (H\&E) staining, the slides were observed and photographed using optical microscopy (DM4000M; Leica Microsystems, GmbH, Wetzlar, Germany), and the results were reviewed by certified veterinary pathologists.

TEM inspection. To evaluate ultrastructural alterations to the tissue, the heart tissues was examined for using TEM. Sections were prepared for examination as previously described (34). Ultrathin sections (70-100 nm) were cut with an LKB-V ultramicrotome (Bromma, Stockholm, Sweden), and identified and analyzed by independent pathologists using TEM (H-600; Hitachi, Ltd., Tokyo, Japan).
Immunohistochemistry examination. Protein expression was detected immunohistochemically in the heart tissues sections. The sections were dewaxed and hydrated in gradient ethyl alcohol. In order to quench endogenous peroxide activity, the sections were treated with $3 \%$ hydrogen dioxide solution for $10 \mathrm{~min}$ at $37^{\circ} \mathrm{C}$, washed and blocked with $10 \%$ immune goat serum (cat. no. DA 1010; Solarbio Life Sciences, Beijing, China) for $10 \mathrm{~min}$ at $37^{\circ} \mathrm{C}$. The sections were incubated overnight at $4^{\circ} \mathrm{C}$ with rabbit anti-Bax (cat. no. NB7185; 1:400; Servicebio, Inc., Woburn, MA, USA), anti-Bcl-2 (cat. no. 2876S; 1:500) or anti-Caspase-3 (cat. no. 9654S, 1:400; Cell Signaling Technology, Inc., Danvers, MA, USA), and incubated with the relevant secondary antibody [goat anti-rabbit IgG-HRP; cat. no. GB23204; 1:2,000; Servicebio, Inc.] at room temperature for $50 \mathrm{~min}$. Following washing, the slides were incubated with HRP-labeled streptavidin (room temperature, $10 \mathrm{~min}$ ), stained with 3-3'diaminobenzidine substrate (room temperature, $30 \mathrm{sec}$ ) and hematoxylin (room temperature, $2 \mathrm{~min}$ ), and examined under an optical microscope. Brown or yellow-stained cells were quantified as positive staining for each high-power field (magnification, x400). Results are expressed as the total positive numbers of 50 random and continuous fields from each section using the software Image Pro Plus 6.0 (Media Cybernetics, Inc., Rockville, MD, USA). All analyses were performed in a blinded manner without prior knowledge of the experimental groups.

Detection of apoptosis. The heart tissues of the rats were processed as mentioned above for terminal deoxynucleotidyl-transferase-mediated dUTP nick end labelling (TUNEL) using an in situ cell death detection kit, according to the manufacturer's protocol (Chemicon International; Thermo Fisher Scientific, Inc., Waltham, MA, USA). Briefly, rat hearts $(n=4)$ from the normal control and three exposure groups were fixed with $4 \%$ paraformaldehyde in $0.1 \mathrm{M}$ phosphate buffer ( $\mathrm{pH} 7.4$; room temperature, $25 \mathrm{~min}$ ) and sliced. Sections were incubated with proteinase $\mathrm{K}(100 \mathrm{~g} / \mathrm{ml})$, and further incubated in $3 \% \mathrm{H}_{2} \mathrm{O}_{2}$. The slides were incubated in TUNEL reaction mixture, counterstained with Mayer's hematoxylin at room temperature for $5 \mathrm{sec}$ and rinsed immediately. PBS was used as the rinsing reagent. Slides were mounted with Permount $^{\mathrm{TM}}$ Mounting Medium. TUNEL-positive cells were stained yellow. Positive results were denoted by a yellow- or brown-stained nucleus. The apoptotic index of cardiomyocytes was evaluated to analyze differences between groups. The apoptosis index was determined from 10 blindly selected high-power fields for each slice by counting the number of positive cells in 500-1,000 cells/field to calculate the percentage of positive cells.

Protein expression analysis by western blotting. Western blotting was used to detect the protein expression of Bax, Bcl-2 and caspase-3. The hearts were weighed and homogenized subsequent to washing with PBS, followed by resuspension in homogenization buffer [1.0 M Tris- $\mathrm{HCl}(\mathrm{pH} 6.8) 1.0 \mathrm{ml}$; $10 \%$ SDS $6.0 \mathrm{ml} ; \beta$-mercaptoethanol $0.2 \mathrm{ml}$; dd $\mathrm{H}_{2} \mathrm{O} 2.8 \mathrm{ml}$, and the tissues were centrifuged for $10 \mathrm{~min}\left(13,400 \mathrm{x} \mathrm{g} ; 4^{\circ} \mathrm{C}\right)$. The supernatants were collected, and $30 \mu \mathrm{g}$ protein from the supernatant of each sample was loaded on SDS-PAGE gels $(12 \%$ resolving gels at $120 \mathrm{~V}, 5 \%$ stacking gels at $75 \mathrm{~V})$. 
Protein samples were transferred to PVDF membranes (200 mA, 1 h; EMD Millipore, Billerica, MA, USA), which were blocked with 5\% nonfat dry milk at room temperature for $1 \mathrm{~h}$, followed by incubation with rabbit anti-Bax (cat. no. NB7185; 1:200; Servicebio, Inc.), anti-Bcl-2 (cat. no. $2876 \mathrm{~S} ; 1: 400$ ) or anti-Caspase-3 (cat. no. 9654S; 1:400; both Cell Signaling Technology, Inc.), and GAPDH (Abcam, Cambridge, UK) overnight at $4^{\circ} \mathrm{C}$. Following washing in TBS with Tween-20 (TBST), the membranes were incubated with secondary antibodies (HRP-conjugated Goat Polyclonal antibody against Rabbit IgG; cat. no. sc-2004; 1:3,000; Santa Cruz Biotechnology, Inc., Dallas, TX, USA) for $0.5 \mathrm{~h}$ at room temperature. Following washing with TBST, the blots were treated with enhanced chemiluminescence (ECL detection kit; Pierce; Thermo Fisher Scientific, Inc.). The optical density of the blots was analyzed using AlphaEaseFC software (Version 4.0.0; ProteinSimple, San Jose, CA, USA). Experiments were performed in triplicate.

Statistical analyses. Data are presented as the mean \pm standard deviation. Statistical analysis was performed using one-way analysis of variance. Data for each group were compared with the other groups using the least significant difference test for significance. All the statistical analyses were performed using SPSS software 20.0 (IBM Corp., Armonk, NY, USA). P<0.05 was considered to indicate a statistically significant difference.

\section{Results}

Characterization of silica nanoparticles. An image of the silica nanoparticles is presented in Fig. 1. Particles were ellipsoidal, of approximately equal size and uniformly distributed, with good mono-dispersity during the experiment. The average particle diameter was $60.80 \pm 4.36 \mathrm{~nm}$, and the average hydrodynamic diameter was $99.5 \pm 6.47 \mathrm{~nm}$ in $0.9 \%$ normal saline (Table I). Due to the Van der Waals forces and hydrophobic interactions, the hydrodynamic size of silica nanoparticles in the dispersion media was increased compared with the particle diameter. The LAL assay revealed no detectable Gram-negative endotoxin on the silica nanoparticles (Table I).

General toxicity induced by silica nanoparticles in rats. Compared with the control group, the average difference in weight in the $10 \mathrm{mg} / \mathrm{kg} \cdot \mathrm{bw}$ group was significantly decreased. As the dosage increased, the heart index exhibited an increasing trend, while the average difference in weight exhibited a decreasing trend, as presented in Table II.

Silica nanoparticles cause hematological alterations in rats. As presented in Fig. 2, there was a significant increase in the PLT and WBC levels compared with the control group, and a significant decrease in the total RBC count. As the dosage increased, the levels of PLT and WBC increased, while the levels of HGB and RBC decreased. A significant upregulation in WBC levels was observed in the $10 \mathrm{mg} / \mathrm{kg} \cdot \mathrm{bw}$ group compared with the 2 and $5 \mathrm{mg} / \mathrm{kg} \cdot \mathrm{bw}$ groups (Fig. 2A). In the 5 and $10 \mathrm{mg} / \mathrm{kg} \cdot \mathrm{bw}$ groups, the PLT level was significantly increased compared with the $2 \mathrm{mg} / \mathrm{kg} \cdot \mathrm{bw}$ group (Fig. 2B). Compared with the control group, the concentration of
Table I. Characterization of amorphous silica nanoparticles in normal saline.

Characteristic

Nano-Si60

Size and distribution, $\mathrm{nm}$

$60.80 \pm 4.36$

(mean \pm standard deviation)

Hydrodynamic size in normal saline, $\mathrm{nm}$

$99.5 \pm 6.47$

(mean \pm standard deviation)

Shape

Aggregation

Spheroid

Crystalline structure

Absent

Endotoxin determination ${ }^{a}$

Amorphous

a(-) Endotoxin free.

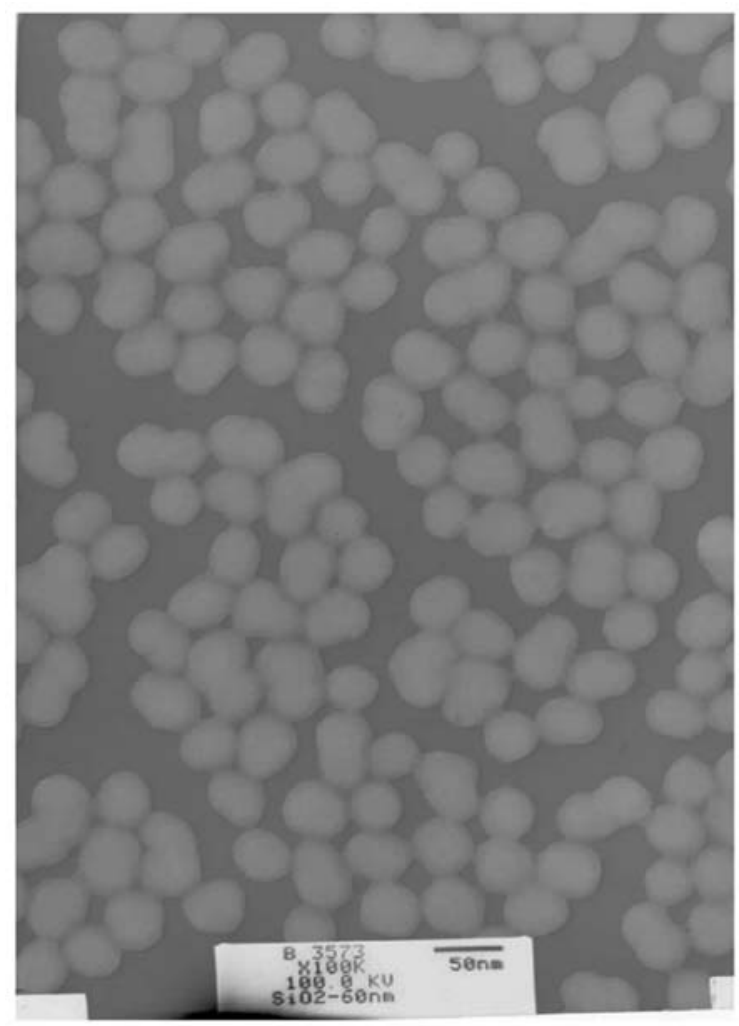

Figure 1. Transmission electron microscope image of amorphous silica nanoparticles.

HGB was significantly decreased in the 5 and $10 \mathrm{mg} / \mathrm{kg} \cdot \mathrm{bw}$ groups (Fig. 2C).

Si concentration in the hearts and serum of silica nanoparticle-exposed rats. Si concentration exhibited a dose-response relationship with exposure dose (Fig. 3). Compared with the control group, the Si concentrations in the hearts and serum of each the treated groups were increased significantly. Si concentrations in the hearts and serum of the $10 \mathrm{mg} / \mathrm{kg} \cdot \mathrm{bw}$ group increased significantly compared with the $5 \mathrm{mg} / \mathrm{kg} \cdot \mathrm{bw}$ and $2 \mathrm{mg} / \mathrm{kg} \cdot \mathrm{bw}$ groups. A significant increase in the $\mathrm{Si}$ serum concentration was also observed in the $5 \mathrm{mg} / \mathrm{kg} \cdot \mathrm{bw}$ group compared with the $2 \mathrm{mg} / \mathrm{kg} \cdot \mathrm{bw}$ group. 
Table II. Effects of silica nanoparticles on body weight and organ coefficients of heart in rats (mean \pm standard deviation; $\mathrm{n}=8$ ).

\begin{tabular}{lccrr}
\hline Groups & Weight prior to exposure, $g$ & Weight following final exposure, $g$ & Difference in weight, $g$ & Index of heart \\
\hline Control & $203.29 \pm 6.85$ & $312.67 \pm 36.88$ & 109.38 & $0.0062 \pm 0.005$ \\
$2 \mathrm{mg} / \mathrm{kg} \cdot \mathrm{bw}$ & $201.38 \pm 6.80$ & $310.74 \pm 30.18$ & 99.36 & $0.0062 \pm 0.004$ \\
$5 \mathrm{mg} / \mathrm{kg} \cdot \mathrm{bw}$ & $208.36 \pm 5.64$ & $310.26 \pm 29.69$ & 101.90 & $0.0063 \pm 0.008$ \\
$10 \mathrm{mg} / \mathrm{kg} \cdot \mathrm{bw}$ & $209.38 \pm 10.21$ & $288.36 \pm 34.67$ & $78.96^{\mathrm{a}}$ & $0.0071 \pm 0.003$
\end{tabular}

${ }^{\mathrm{a}} \mathrm{P}<0.05$ vs. control group.
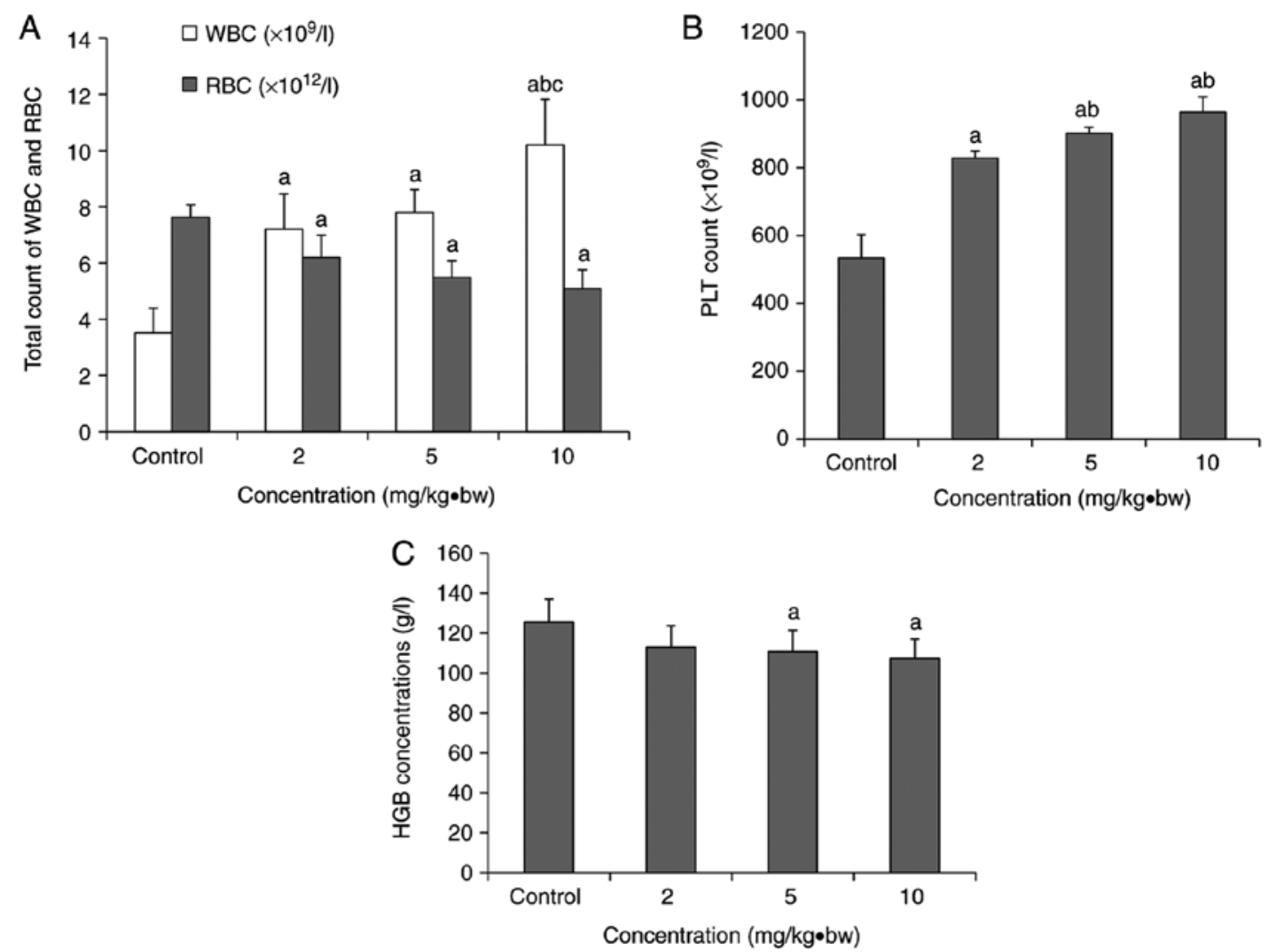

Figure 2. Hematological alterations in rats following exposure to silica nanoparticles. (A) The total WBC and RBC counts in each dose group. (B) Platelets count in each dose group. (C) Concentrations of HGB in each dose group (mean \pm standard deviation; $n=8$ ). ${ }^{a} \mathrm{P}<0.05$ vs. respective control group; ${ }^{\mathrm{b}} \mathrm{P}<0.05$ vs. respective $2 \mathrm{mg} / \mathrm{kg} \cdot \mathrm{bw}$ group; ${ }^{\mathrm{C}} \mathrm{P}<0.05 \mathrm{vs}$. respective $5 \mathrm{mg} / \mathrm{kg}$-bw group. WBC, white blood cell; RBC red blood cell; PLT, platelets; HGB, hemoglobin; bw, body weight.
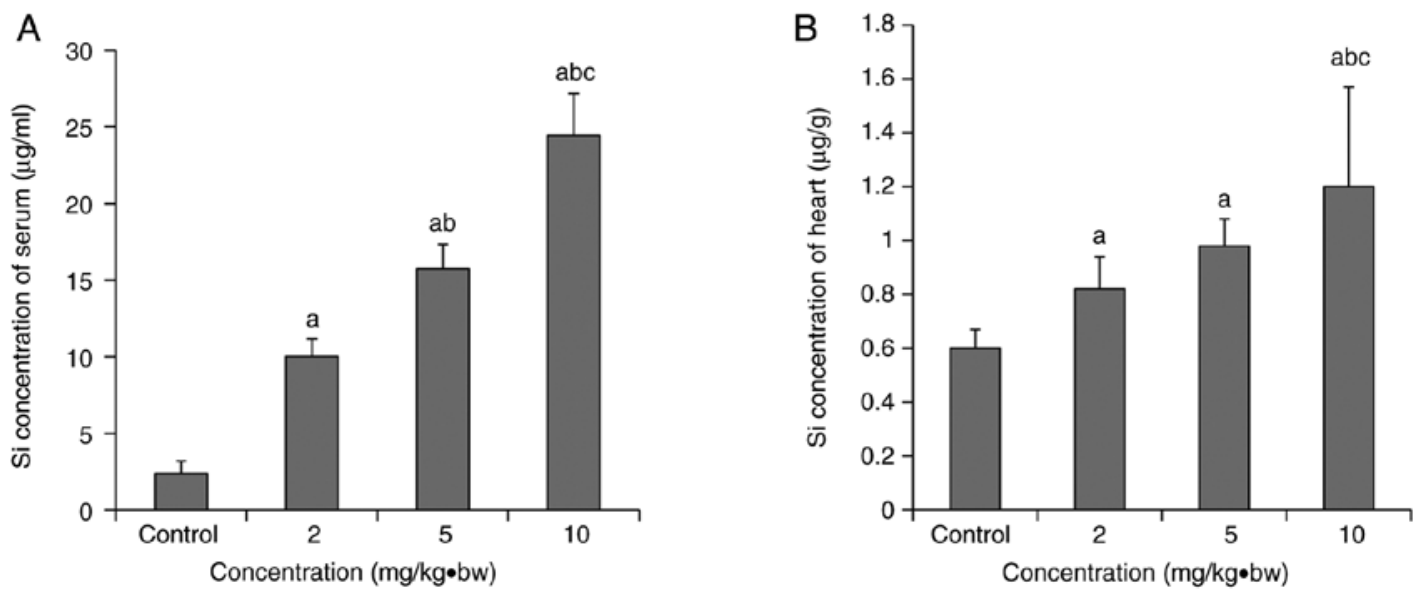

Figure 3. Si concentration in the serum and the heart following intratracheal instillation (mean \pm standard deviation; $\mathrm{n}=8$ ). (A) Si concentration in the serum; (B) Si concentration in the heart. ${ }^{\mathrm{P}} \mathrm{P}<0.05 \mathrm{vs}$. control group; ${ }^{\mathrm{b}} \mathrm{P}<0.05 \mathrm{vs} .2 \mathrm{mg} / \mathrm{kg} \cdot \mathrm{bw}$ group; ${ }^{\mathrm{C}} \mathrm{P}<0.05 \mathrm{vs}$. $5 \mathrm{mg} / \mathrm{kg} \cdot \mathrm{bw}$ group. bw, body weight. 

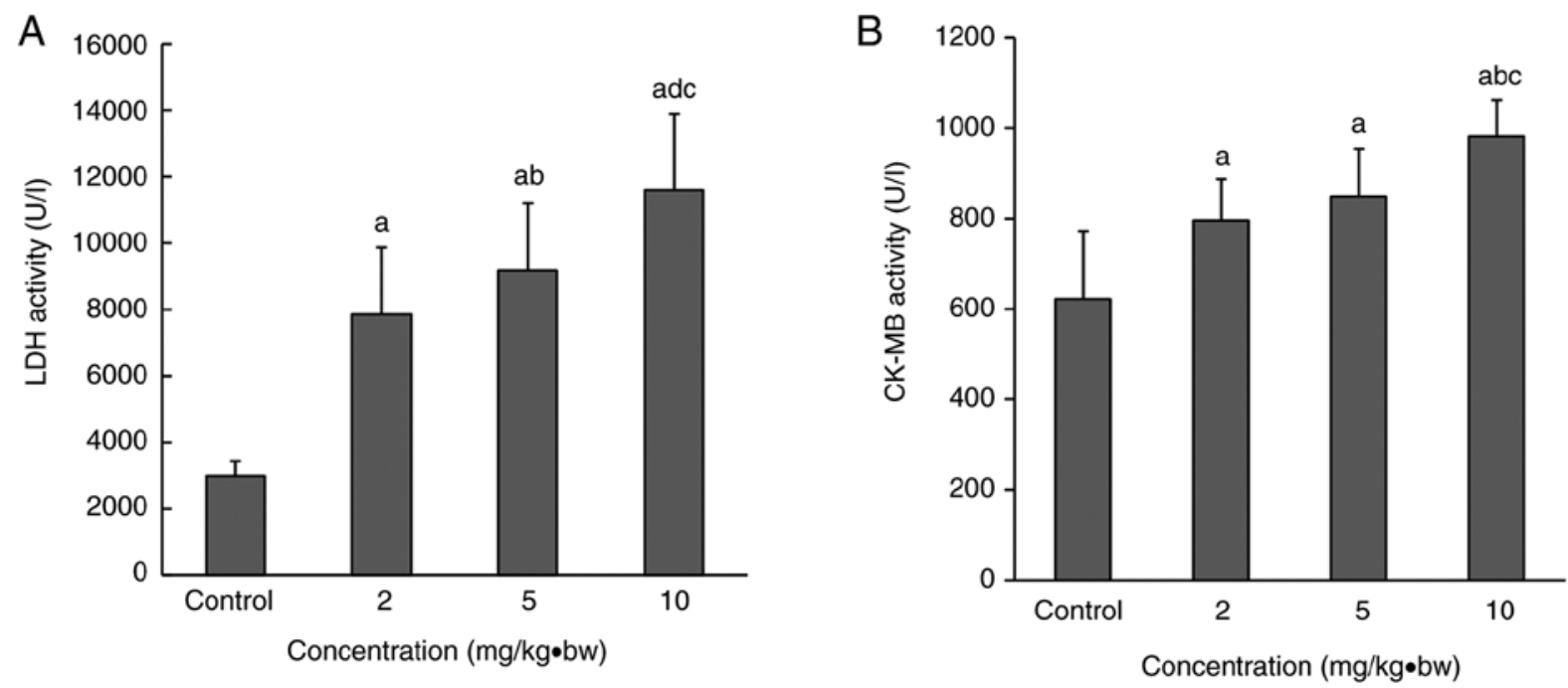

Figure 4. LDH and CK-MB levels in the serum following intratracheal instillation. Serum (A) LDH and (B) CK-MB activities in each dose group were significantly upregulated compared with the control group. A significant increase was also observed in the $10 \mathrm{mg} / \mathrm{kg} \cdot \mathrm{bw}$ group compared with the 2 and $5 \mathrm{mg} / \mathrm{kg} \cdot \mathrm{bw}$ groups. Compared with the $2 \mathrm{mg} / \mathrm{kg} \cdot \mathrm{bw}$ group, LDH activity was significantly upregulated in the $5 \mathrm{mg} / \mathrm{kg} \cdot \mathrm{bw}$ group. ${ }^{\mathrm{a}} \mathrm{P}<0.05 \mathrm{vs}$. control group; ${ }^{\mathrm{b}} \mathrm{P}<0.05$ vs. $2 \mathrm{mg} / \mathrm{kg} \cdot$ bw group; ${ }^{\mathrm{C}} \mathrm{P}<0.05$ vs. $5 \mathrm{mg} / \mathrm{kg} \cdot$ bw group. CK-MB, creatine kinase-MB; LDH, lactate dehydrogenase; bw, body weight.

Abnormal serum myocardial enzymes in silica-treated rats. Serum LDH and CK-MB activity in the rats in each dose group following intratracheal instillation were significantly upregulated compared with the control group (Fig. 4). A significant increase was also observed the in $10 \mathrm{mg} / \mathrm{kg} \cdot \mathrm{bw}$ group compared with the 2 and $5 \mathrm{mg} / \mathrm{kg} \cdot \mathrm{bw}$ groups. Compared with the $2 \mathrm{mg} / \mathrm{kg} \cdot \mathrm{bw}$ group, LDH activity was significantly upregulated in the $5 \mathrm{mg} / \mathrm{kg} \cdot \mathrm{bw}$ group (Fig. 4A).

Silica exposure results in histopathological alterations. Morphological alterations in myocardial paraffin slices are presented in Fig. 5. In the control group, cardiomyocytes had homogeneous cytoplasm and normal intercellular space, cardiac muscle fibers were arranged in an orderly manner without breakage, and edema was not observed in the cells or intercellular space. In exposed rats, enlarged intercellular space, fragmented cardiac muscle fibers and obscure boundaries of cardiomyocytes were noted. Proliferation of myocardial fibrous tissue and pyknotic cardiomyocytes were observed in rats from the $10 \mathrm{mg} / \mathrm{kg} \cdot \mathrm{bw}$ group, with the absence of transverse striation of cardiomyocytes in the pyknotic areas. These histological alterations indicated damage to the cardiomyocytes with an increasing trend as the nanoparticle dose increased.

Ultrastructural alterations in the heart tissue of exposed rats. In rats from the control group, cardiac muscle fibers were observed to be in an orderly arrangement, the mitochondrial membrane was intact as was the intercalated disc, and the endocardial crest was of a normal density (Fig. 6). In rats from the $10 \mathrm{mg} / \mathrm{kg} \cdot \mathrm{bw}$ group, broken cardiac muscle fibers and dissociated intercalated discs were observed. The mitochondrial membrane was swollen, pyknotic and partially cavitated, while the mitochondria appeared vacuolized and the mitochondrial cristae were broken or absent. The collagenous fiber in the intercellular substance was found to be increased. High electron density particles were observed the in mitochondria and within the cytoplasm of endothelial cells.

Abnormal cardiomyocytes in rats exposed to silica nanoparticles. Apoptosis was detected by TUNEL assay. Negative staining was blue, while positive staining was yellow or brown in the nucleus. It is illustrated in Fig. 7 that there was a larger number of brown-stained cardiomyocyte nuclei in the treated groups, with the number as the dose increased. An increased apoptosis index in the 2, 5 and $10 \mathrm{mg} / \mathrm{kg} \cdot \mathrm{bw}$ groups was observed compared with the control group. There was a significant upregulation in the higher dose group (10 mg/kg.bw) compared with the medium and low dose ( 2 and $5 \mathrm{mg} / \mathrm{kg} \cdot \mathrm{bw})$ groups. The apoptosis index had an increasing trend as the dose increased, as exhibited in Fig. 7B.

\section{Expression levels of cardiomyocyte apoptosis-associated proteins}

Immunohistochemistry analysis. Positive expression of each protein in the nucleus was demonstrated by dark blue staining, whereas the cytoplasm appeared faint yellow or brown (Fig. 8A). The expression of Bax and caspase-3 proteins in the myocardium of rats from the exposure groups was significantly increased compared with the control group (Fig. 8B). It was additionally observed that $\mathrm{Bcl}-2$ expression levels in each dose group were significantly decreased compared with the control group (Fig. 8B). A significant upregulation of expression of Caspase-3 was observed in the $10 \mathrm{mg} / \mathrm{kg} \cdot \mathrm{bw}$ group compared with $2 \mathrm{mg} / \mathrm{kg} \cdot \mathrm{bw}$ group.

Western blot analysis. As presented in Fig. 9, the expression levels of Bax and caspase-3 proteins in each dose group were significantly increased, and this was most evident for Bax in the higher dose group $(10 \mathrm{mg} / \mathrm{kg} \cdot \mathrm{bw})$. A significant upregulation of caspase- 3 expression was observed in the high dose and medium dose groups ( 5 and $10 \mathrm{mg} / \mathrm{kg} \cdot \mathrm{bw}$ ) compared with 
A

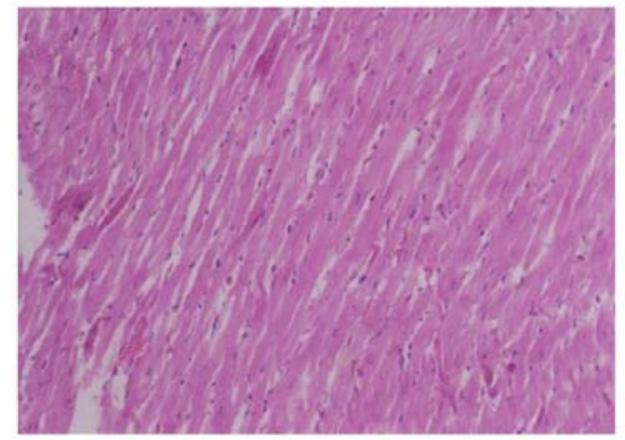

C

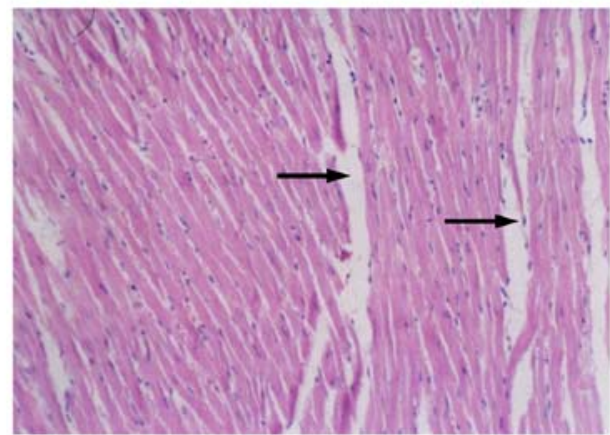

B

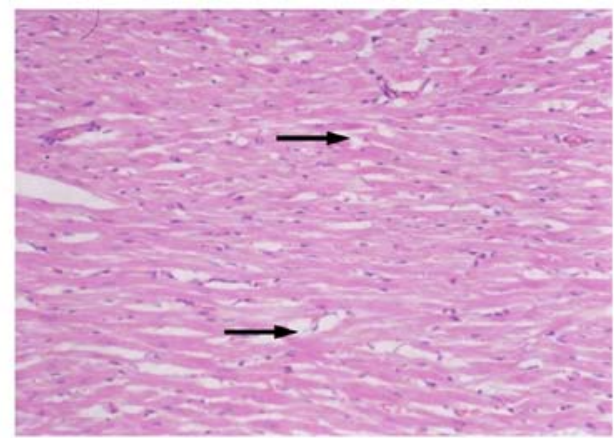

D

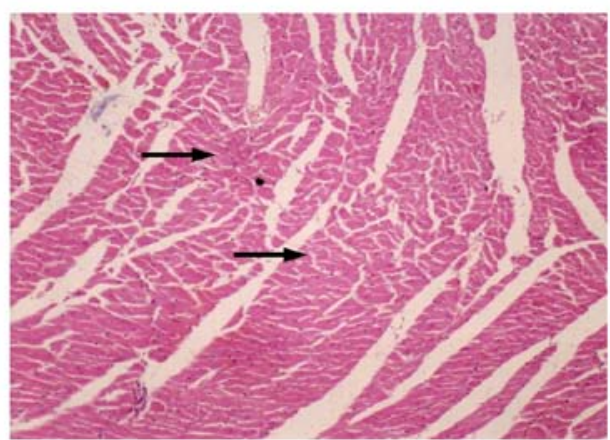

Figure 5. Histopathological alterations in cardiomyocytes following intratracheal instillation of silica nanoparticles in rats (magnification, $\mathrm{x} 200$ ). (A) Control group; (B) $2 \mathrm{mg} / \mathrm{kg} \cdot \mathrm{bw}$ group; (C) $5 \mathrm{mg} / \mathrm{kg} \cdot \mathrm{bw}$ group; (D) $10 \mathrm{mg} / \mathrm{kg} \cdot \mathrm{bw}$ group. In the control group, the cardiomyocytes had a normal morphology. In exposed rats, enlarged intercellular space, fragmented cardiac muscle fibers and obscure boundaries of cardiomyocytes were observed. Histological alterations appeared to increase as the dose increased. Black arrows indicate damaged cardiomyocytes. bw, body weight.

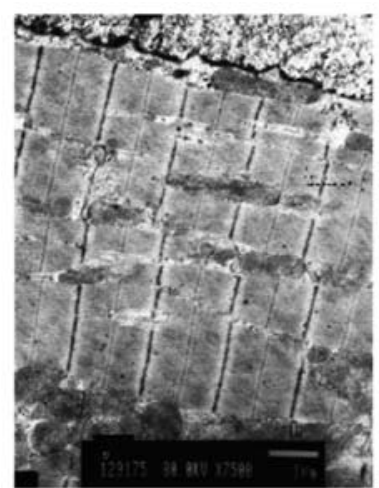

Control group

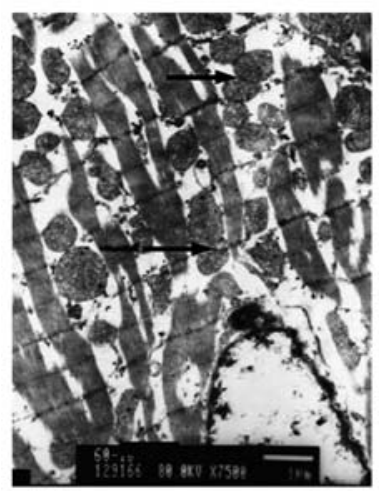

$5 \mathrm{mg} / \mathrm{kg} \cdot \mathrm{bw}$ group

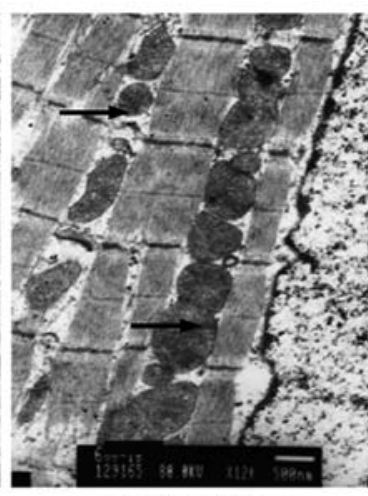

$2 \mathrm{mg} / \mathrm{kg} \cdot \mathrm{bw}$ group

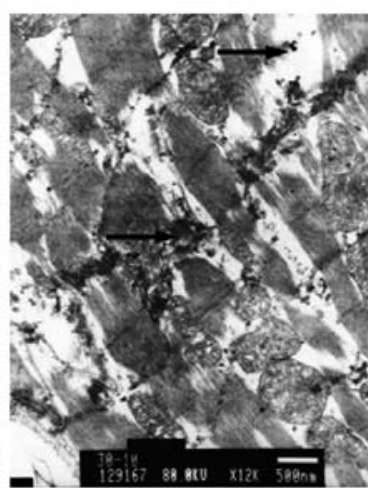

$10 \mathrm{mg} / \mathrm{kg} \cdot \mathrm{bw}$ group
Figure 6. Electron microscopy of cardiomyocytes in rats. In the control group, the cardiomyocytes had a normal morphology. In exposed rats, broken cardiac muscle fibers and dissociated intercalated discs were observed. The mitochondrial membrane was swollen, pyknotic and partially cavitated, while the mitochondria appeared to exhibit vacuolization, and the mitochondrial cristae were broken or absent. Histological alterations appeared to increase as the dose increased. Black arrows indicate intercalated disc dissociation. bw, body weight. the low dose group ( $2 \mathrm{mg} / \mathrm{kg} \cdot \mathrm{bw})$. Meanwhile, the ratios of $\mathrm{Bcl}-2 / \mathrm{Bax}$ in each dose group were significantly decreased compared with the control group, and that in high dose group was significantly decreased compared with the low dose group (Fig. 9B).

\section{Discussion}

Previous studies have reported that the physical and chemical properties of nanoparticles, including morphology, size and dispersion/aggregation, may affect their biological behavior (35). In order to investigate the biologicaleffect and mechanism of nanomaterials, certain physical and chemical characteristics (particle size, distribution, structure and state of dispersion/aggregation in biological environment) should be carefully controlled (8). In this study, the morphology and particle size of silica nanoparticles were examined by TEM, and the differences between the dried state and that in solution in $0.9 \%$ normal saline were compared. TEM images indicated that silica nanoparticles were ellipsoidal, of approximately equal size and uniformly distributed, with good mono-dispersity. Meanwhile, the particles also had a larger size $(99.5 \pm 6.47 \mathrm{~nm})$ compared with the original size $(60.80 \pm 4.36 \mathrm{~nm})$, most likely due to the hydrodynamic size of particles formed in solution (36).

Inhaled nanoparticles not only affect the respiratory system, but also other organs by entering the circulatory system via the blood-air barrier in the lungs $(37,38)$. It was identified that the toxicity symptoms in rats became more prominent as the exposure time was prolonged and the dose increased (data not shown). In our previous study, it was noted that following exposure to silica nanoparticles in male Wistar rats, blood parameters (WBCs and platelets) increased in a dose-dependent 


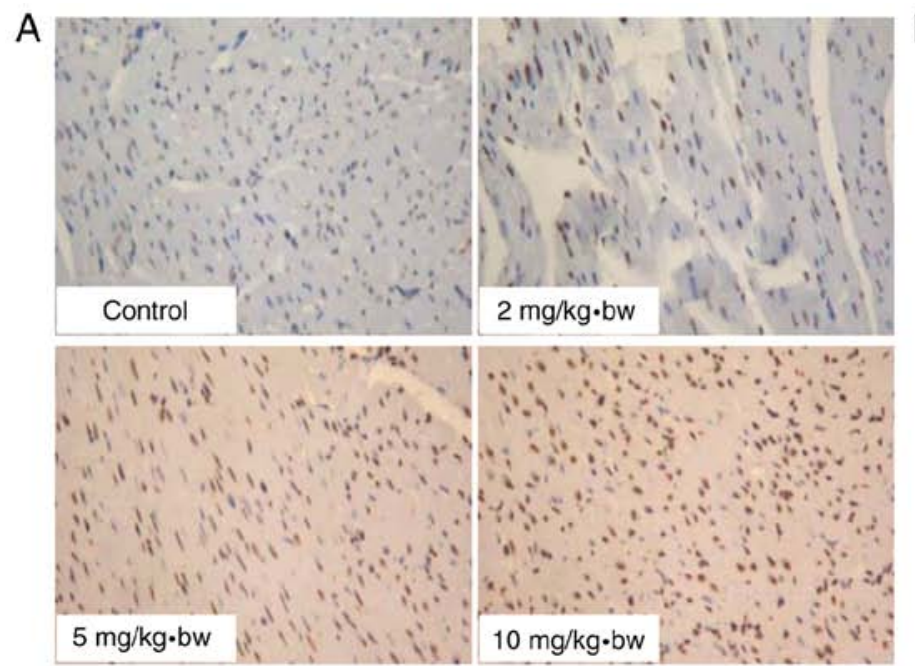

B

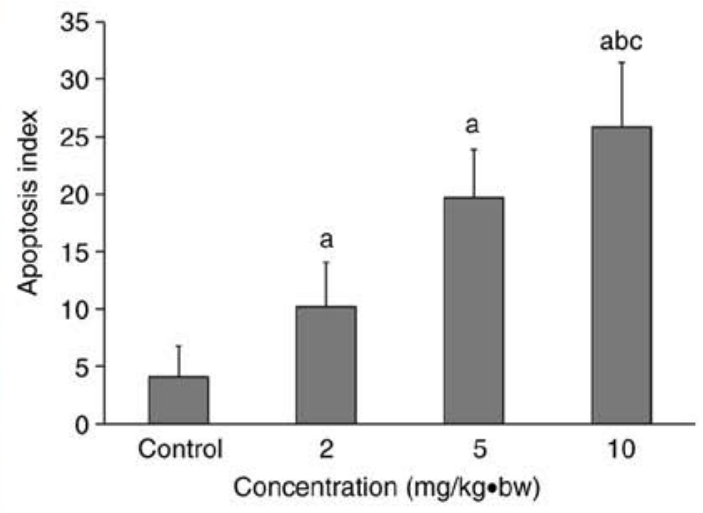

Figure 7. Cardiomyocyte apoptosis in rats following intratracheal instillation of silica nanoparticles. (A) Cardiomyocyte apoptosis and (B) apoptosis indexes of each group following exposure to silica nanoparticles, as assessed by terminal deoxynucleotidyl-transferase-mediated dUTP nick end labelling (magnification, $\mathrm{x} 200$ ). ${ }^{a} \mathrm{P}<0.05$ vs. control group; ${ }^{\mathrm{b}} \mathrm{P}<0.05 \mathrm{vs.} 2 \mathrm{mg} / \mathrm{kg} \cdot$ bw group; ${ }^{\mathrm{C}} \mathrm{P}<0.05 \mathrm{vs} .5 \mathrm{mg} / \mathrm{kg} \cdot$ bw group. bw, body weight.

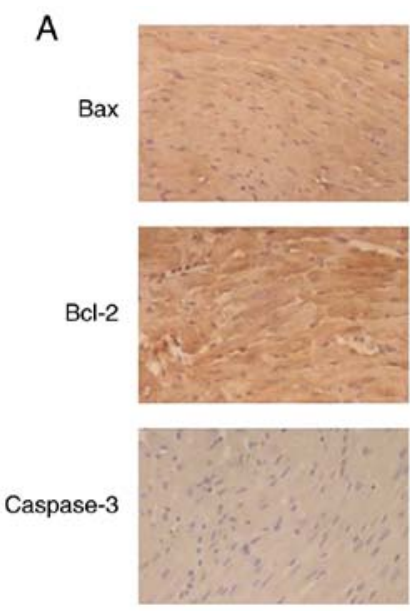

Control group
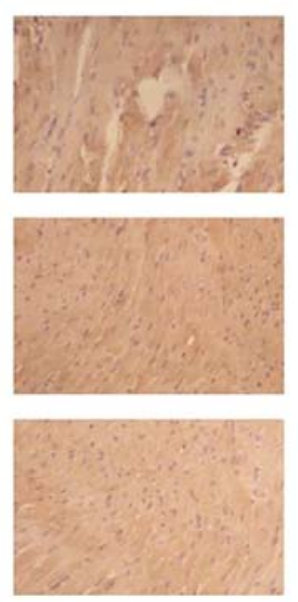

$2 \mathrm{mg} / \mathrm{kg} \cdot \mathrm{bw}$
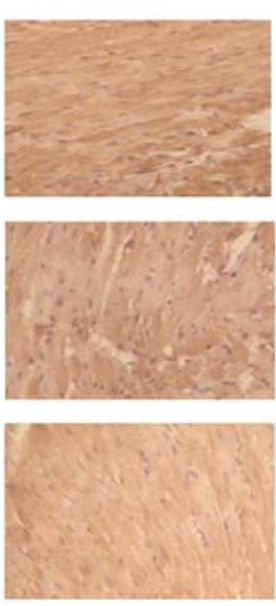

$5 \mathrm{mg} / \mathrm{kg} \cdot \mathrm{bw}$
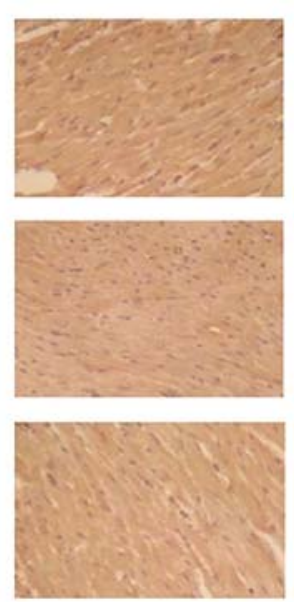

$10 \mathrm{mg} / \mathrm{kg} \cdot \mathrm{bw}$
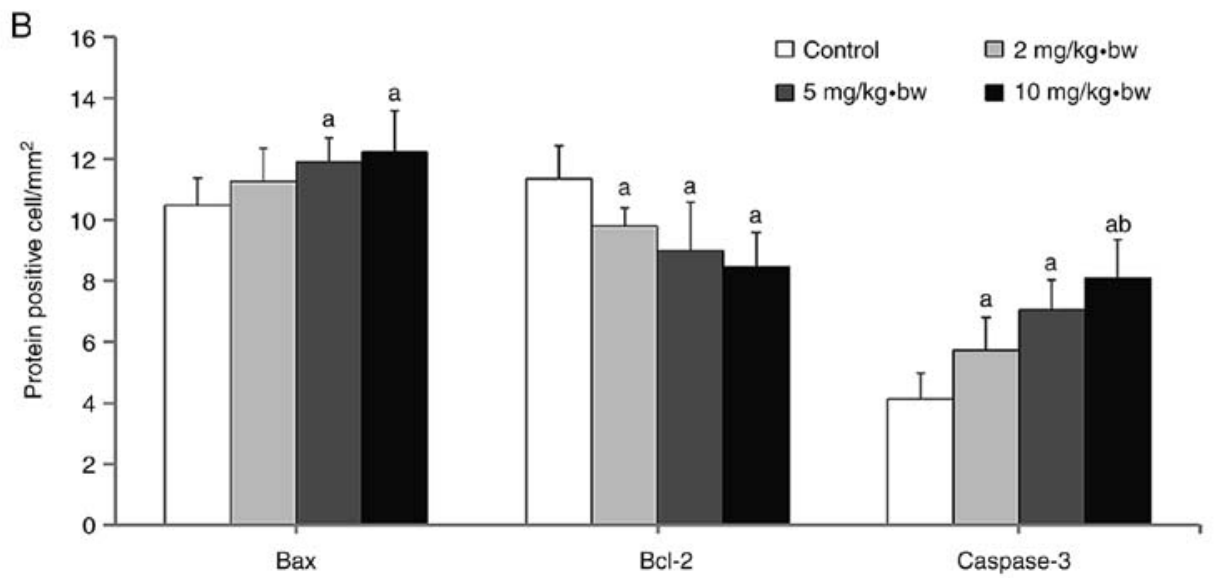

Figure 8. Measurement of Bax, Bcl-2 and caspase-3 protein expression in that cardiomyocytes of rats following exposure to silica nanoparticles. (A) Representative immunohistochemical images of Bax, Bcl-2 and caspase-3 proteins are presented (magnification, x200). (B) Quantification of the number of cells expressing these proteins in the cardiomyocytes of rats. ${ }^{a} \mathrm{P}<0.05$ vs. control group; ${ }^{b} \mathrm{P}<0.05 \mathrm{vs} .2 \mathrm{mg} / \mathrm{kg} \cdot \mathrm{bw}$ group. Bax, apoptosis regulator BAX; Bcl-2, apoptosis regulator $\mathrm{Bcl}-2$; bw, body weight.

manner $(2,5$ or $10 \mathrm{mg} / \mathrm{kg} \cdot \mathrm{bw} / \mathrm{day}$ for 16 days) (33). In the study of Morris et al (39), the number of neutrophils in the bronchoalveolar lavage fluid of mice treated with bare and amine-coated silica nanoparticles increased by $20-30$ times 

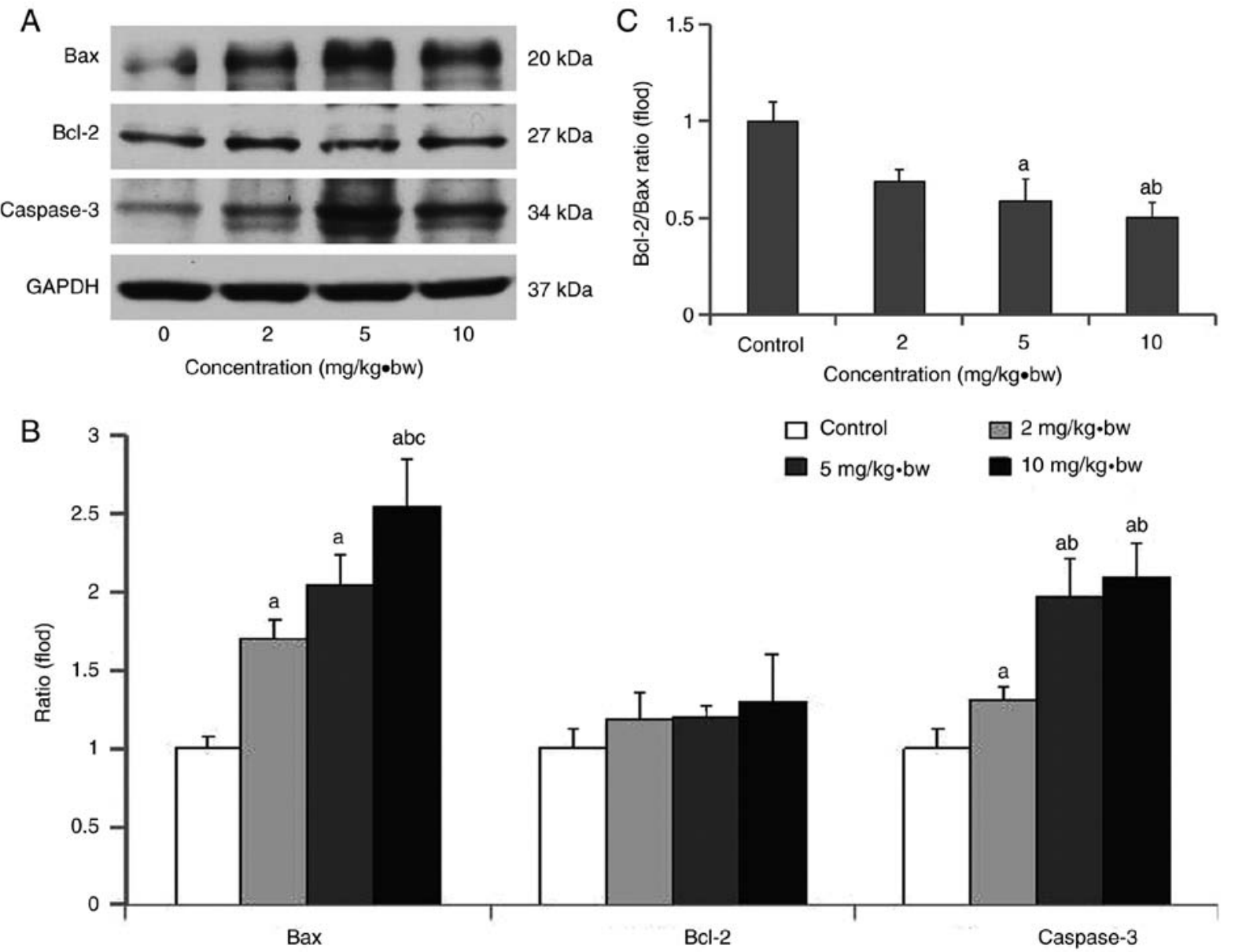

Figure 9. Bax, Bcl-2 and caspase-3 expression levels, and the Bcl-2/Bax ratio, in rat cardiomyocytes following exposure to silica nanoparticles. (A) Western blotting of Bax, Bcl-2 and caspase-3 at different exposure concentrations; (B) ratio of Bcl-2/Bax at different exposure concentrations; (C) quantification of protein expression at different exposure concentrations. ${ }^{a} \mathrm{P}<0.05 \mathrm{vs}$. control group; ${ }^{\mathrm{b}} \mathrm{P}<0.05 \mathrm{vs} .2 \mathrm{mg} / \mathrm{kg} \cdot \mathrm{bw}$ group; ${ }^{\mathrm{C}} \mathrm{P}<0.05 \mathrm{vs}$. $5 \mathrm{mg} / \mathrm{kg} \cdot \mathrm{bw} \mathrm{group}$. Bax, apoptosis regulator BAX; Bcl-2, apoptosis regulator Bcl-2; bw, body weight.

compared with the control group $20 \mathrm{~h}$ after silica nanoparticle intratracheal injection. Kim et al (40) exposed C57BL/6 mice to colloidal silicon dioxide nanoparticles (20 and $100 \mathrm{~nm})$, modified with or without $\mathrm{L}$-arginine, to determine the effect of surface charge on immunotoxicity in vivo; 14 days subsequently, it was observed that the WBC count and cytokines were reduced in a size-dependent manner. In the present study, it was identified that rats intratracheally instilled with $60 \mathrm{~nm}$ silica nanoparticles exhibited hematological toxicity. These parameters reflected the effects of silica nanoparticles and the later onset of apoptosis. The Si content in the heart and serum of the rats in the exposure groups was significantly higher, with dose-effect relationship to a certain degree, suggesting that silica nanoparticles may be transferred into the circulatory system through the respiratory tract and be distributed in the cardiac tissue. The activity of LDH and CK-MB in the rats increased, which may indicate possible ischemia and necrosis in the heart. Histological examination of the myocardial structure of rats exposed to nanoparticles indicated that the extent of injury to the myocardium was aggravated as the dose of nanoparticles increased. All these results not only provided an explanation for the epidemiological findings that inhaled superfine particles may affect the cardiovascular system, but also confirmed the toxic effects of inhaled nanoparticles on the heart, which is consistent with previous reports (16-19).
The maintenance of normal mitochondrial morphology is important for well-balanced cellular functions (41). Mitochondria serve a key role in initiating and amplifying signals in the majority of apoptotic pathways. Apoptosis is an important way of maintaining the basic physiological activities of the human body. The feedback loops and interactions of various mitochondrial death pathways make mitochondria the most important component of apoptosis pathways (42). Apoptosis serves a critical role in normal cell renewal, the removal of abnormal cells and organ function. A previous study demonstrated that cardiomyocyte apoptosis may have a marked influence on the occurrence of congestive heart failure (43). Bcl-2 family proteins include pro-apoptotic proteins such as Bax, and anti-apoptotic proteins such as Bcl-2 protein. These proteins regulate apoptosis by mediating the stimulation of apoptotic signals that reach the mitochondrial membrane and regulate the release of $\mathrm{Cyt} \mathrm{C}$ into the mitochondrial membrane space (44). Bcl-2 is able to reduce mitochondrial permeability, control the release of $\mathrm{Cyt} \mathrm{C}$ into the mitochondrial membrane space and inhibit cysteine-containing aspartate-specific proteases (caspases), and in turn inhibit apoptosis (45). Bax is part of an apoptotic regulatory system that controls apoptosis by forming a homologous dimer or heterodimers with Bcl-2 (46). Since the structure of Bax-Bcl-2 is more stable compared with $\mathrm{Bax}-\mathrm{Bax}$, the ratio of $\mathrm{Bcl}-2 / \mathrm{Bax}$ regulates 
the occurrence of apoptosis and determines cell survival. Additionally, caspase-3 serves an important role in apoptosis and functions by removing inhibition to mediate feedback amplification (47). The caspase family primarily exists in the form of pro-enzymes in cells. Following stimulation by stress or other molecular signals, the caspase family activates initiator caspases and executioner caspases, which elicit apoptosis by degrading substrate proteins (48). Nanoparticles are able to initiate this mitochondria-mediated apoptosis. For example, $\mathrm{CuO}$ nanoparticles have been reported to induce the apoptosis of cells by upregulating the ratio of Bcl-2/Bax, suggesting that the mitochondria-mediated pathway is involved in the apoptosis (49). NiZn ferrite nanoparticles promote the apoptosis of cancer cells by regulating proteins in the mitochondrial pathway, including caspase-3, caspase-9, Bax, Bcl-2 and Cyt C (50). In in vitro experiments with $\mathrm{ZnO}$ nanoparticles, a decrease in the cell viability of HepG2 cells exposed to $14-20 \mu \mathrm{g} / \mathrm{m} \mathrm{ZnO}$ nanoparticles was associated with a decrease in mitochondrial membrane potential and an increase in the $\mathrm{Bax} / \mathrm{Bcl}-2$ ratio, induced by reactive oxygen species (51).

In the present study, exposure to silica nanoparticles caused histological and ultrastructural alterations in a dose-dependent manner, which indicated the destruction of cardiomyocytes with mitochondrial damage. Cardiomyocyte apoptosis was assessed by TUNEL assay, and the expression levels of Bax, Bcl-2 and caspase- 3 proteins by western blotting. These findings suggested that mitochondrial apoptosis may occur in cardiomyocytes, and may be responsible for the observed cell injury and tissue damage in the heart. This may be one of the possible mechanisms leading to the cardiac toxicity caused by silica nanoparticles. In consideration of the mechanism of apoptosis and the preliminary study which demonstrated that silica nanoparticles may cause HepG2 cell apoptosis via the mitochondrial pathway (52), it may be concluded that silica nanoparticles have influences on the expression levels of $\mathrm{Bcl}-2$, Bax and caspase- 3 proteins in cardiomyocytes, and are able to induce cardiomyocyte apoptosis through the mitochondrial pathway. The present study is preliminary work from the point of view of apoptosis, and the purpose of the study was to demonstrate that silica nanoparticles are able to cause cardiovascular toxicity through apoptosis. More work is required to detect the apoptosis pathway, and to further research the mechanism of action of silica nanoparticles in apoptosis pathways.

In conclusion, the present study demonstrated that silica nanoparticles are able to damage the respiratory and cardiovascular systems via the blood-air barrier. Silica nanoparticles induce apoptosis via the mitochondrial pathway, and may serve an important role in the associated adverse cardiac effects.

\section{Acknowledgements}

Not applicable.

\section{Funding}

The present study was funded by the National Natural Science Foundation of China (grant nos. 81602893 and 81872575), the Natural Science Foundation of Shandong Province (grant nos. ZR2015YL049 and ZR2018MH036), the Medical and Health Technology Development Plan Project of Shandong Province (grant no. 2016WS0540), the Key Research and Development Plan of Shandong Province (grant nos. 2017GSF18186 and 2018GSF118018), the Natural Science Foundation of Jiangsu Province (grant no. BK20140573), the Innovation Project of Shandong Academy of Medical Science and the Tsung Cho-Chang Educational Foundation (grant no. UQ-019171).

\section{Availability of data and materials}

The datasets used and/or analyzed during the current study are available from the corresponding author on reasonable request.

\section{Authors' contributions}

$\mathrm{ZD}, \mathrm{SC}$ and GC performed the analysis and interpretation of data, generated the figures and tables, and drafted the manuscript. YY and EZ characterized the silica nanoparticles and analyzed the data. QW, CB, YZ, CL, XL and XY contributed reagents/materials/analysis tools. MFL and AJY provided technical support for the analysis and critical revision of the manuscript. CP and HS designed the study and revised the manuscript. Authors read and approved the final manuscript.

\section{Ethics approval and consent to participate}

All animals were treated according to the experimental protocols and procedures evaluated and approved by the ethical committee of Norman Bethune College of Medicine, Jilin University.

\section{Patient consent for publication}

Not applicable.

\section{Competing interests}

The authors declare that they have no competing interests.

\section{References}

1. Lasfargues M, Stead G, Amjad M, Ding Y and Wen D: In Situ production of copper oxide nanoparticles in a binary molten salt for concentrated solar power plant applications. Materials (Basel) 10: E537, 2017.

2. Ortelli S, Costa A and Dondi M: TiO2 nanosols applied directly on textiles using different purification treatments. Materials (Basel) 8: 7988-7996, 2015.

3. Oliveira MLS, Navarro OG, Crissien TJ, Tutikian BF, da Boit K, Teixeira EC, Cabello JJ, Agudelo-Castañeda DM and Silva LFO: Coal emissions adverse human health effects associated with ultrafine/nano-particles role and resultant engineering controls. Environ Res 158: 450-455, 2017.

4. Shao H, Mohammed MU, Thomas N, Babazadeh S, Yang S, Shi Q and Shi L: Evaluating excessive burden of depression on health status and health care utilization among patients with hypertension in a nationally representative sample from the medical expenditure panel survey (MEPS 2012). J Nerv Ment Dis 205: 397-404, 2017.

5. Hsin YH, Chen CF, Huang S, Shih TS, Lai PS and Chueh PJ: The apoptotic effect of nanosilver is mediated by a ROS- and JNK-dependent mechanism involving the mitochondrial pathway in NIH3T3 cells. Toxicol Lett 179: 130-139, 2008. 
6. Miller M, Raftis JB, Langrish JP, McLean SG, Samutrtai P, Connell SP, Wilson S, Vesey AT, Fokkens PHB, Boere AJF, et al: Inhaled nanoparticles accumulate at sites of vascular disease. Acs Nano 11: 4542-4552, 2017.

7. Kong L, Tang M, Zhang T, Wang D, Hu K, Lu W, Wei C, Liang $\mathrm{G}$ and $\mathrm{Pu} \mathrm{Y}$ : Nickel nanoparticles exposure and reproductive toxicity in healthy adult rats. Int J Mol Sci 15: 21253-21269, 2014.

8. Xia T, Kovochich M and Nel AE: Impairment of mitochondrial function by particulate matter (PM) and their toxic components: Implications for PM-induced cardiovascular and lung disease. Front Biosci 12: 1238-1246, 2007.

9. Miao AJ, Schwehr KA, Xu C, Zhang SJ, Luo Z, Quigg A and Santschi PH: The algal toxicity of silver engineered nanoparticles and detoxification by exopolymeric substances. Environ Pollut 157: 3034-3041, 2009.

10. Geiser M, Rothen-Rutishauser B, Kapp N, Schürch S, Kreyling W, Schulz H, Semmler M, Im Hof V, Heyder J and Gehr P: Ultrafine particles cross cellular membranes by nonphagocytic mechanisms in lungs and in cultured cells Environ Health Perspect 113: 1555-1560, 2005.

11. Renwick LC, Donaldson K and Clouter A: Impairment of alveolar macrophage phagocytosis by ultrafine particles. Toxicol Appl Pharmacol 172: 119-127, 2001.

12. Lanone $\mathrm{S}$ and Boczkowski J: Biomedical applications and potential health risks of nanomaterials: Molecular mechanisms. Curr Mol Med 6: 651-663, 2006.

13. Nan A, Bai X, Son SJ, Lee SB and Ghandehari H: Cellular uptake and cytotoxicity of silica nanotubes. Nano Lett 8: 2150-2154, 2008.

14. Jia G, Wang H, Yan L, Wang X, Pei R, Yan T, Zhao Y and Guo X: Cytotoxicity of carbon nanomaterials: Single-wall nanotube, multi-wall nanotube, and fullerene. Environ Sci Technol 39: $1378-1383,2005$.

15. Nagano T, Nagano K, Nabeshi $H$, Yoshida T, Kamada $H$, Tsunoda SI, Gao JQ, Higashisaka K, Yoshioka Y and Tsutsumi Y: Modifying the surface of silica nanoparticles with amino or carboxyl groups decreases their cytotoxicity to parenchymal hepatocytes. Biol Pharm Bull 40: 726-728, 2017.

16. Duan J, Yu Y, Li Y, Liu H, Jing L, Yang M, Wang J, Li C and Sun Z: Low-dose exposure of silica nanoparticles induces cardiac dysfunction via neutrophil-mediated inflammation and cardiac contraction in zebrafish embryos. Nanotoxicology 10 : $575-585,2016$

17. Duan J, Hu H, Li Q, Jiang L, Zou Y, Wang Y and Sun Z: Combined toxicity of silica nanoparticles and methylmercury on cardiovascular system in zebrafish (Danio rerio) embryos Environ Toxicol Pharmacol 44: 120-127, 2016.

18. Guerrero-Beltrán CE, Bernal-Ramírez J, Lozano O Oropeza-Almazán Y, Castillo EC, Garza JR, García N, Vela J, García-García A, Ortega E, et al: Silica nanoparticles induce cardiotoxicity interfering with energetic status and $\mathrm{Ca} 2+$ handling in adult rat cardiomyocytes. Am J Physiol Heart Circ Physiol 312: H645-H661, 2017.

19. Duan J, Yu Y, Li Y, Huang P, Zhou X, Peng S and Sun Z: Silica nanoparticles enhance autophagic activity, disturb endothelial cell homeostasis and impair angiogenesis. Part Fibre Toxicol 11: $50,2014$.

20. Kreyling WG, Semmler-Behnke M, Takenaka S and Moller W: Differences in the biokinetics of inhaled nano- versus micrometer-sized particles. Acc Chem Res 46: 714-722, 2013

21. Terzano C, Di Stefano F, Conti V, Graziani E and Petroianni A Air pollution ultrafine particles: Toxicity beyond the lung. Eur Rev Med Pharmacol Sci 14: 809-821, 2010.

22. Geiser M: Update on macrophage clearance of inhaled microand nanoparticles. J Aerosol Med Pulm Drug Deliv 23: 207-217, 2010.

23. Semmler-Behnke M, Takenaka S, Fertsch S, Wenk A, Seitz J, Mayer P, Oberdörster G and Kreyling WG: Efficient elimination of inhaled nanoparticles from the alveolar region: Evidence for interstitial uptake and subsequent reentrainment onto airways epithelium. Environ Health Perspect 115: 728-733, 2007.

24. Zanobetti A and Schwartz J: The effect of particulate air pollution on emergency admissions for myocardial infarction: A multicity case-crossover analysis. Environ Health Perspect 113 978-982, 2005.

25. Sullivan J, Sheppard L, Schreuder A, Ishikawa N, Siscovick D and Kaufman J: Relation between short-term fine-particulate matter exposure and onset of myocardial infarction. Epidemiology 16: $41-48,2005$
26. Karacalioglu O, Arslan Z, Kilic S, Öztürk E and Ozguven M: Baseline serum levels of cardiac biomarkers in patients with stable coronary artery disease. Biomarkers 12: 533-540, 2007.

27. Salakou S, Kardamakis D, Tsamandas AC, Zolota V, Apostolakis E, Tzelepi V, Papathanasopoulos P, Bonikos DS Papapetropoulos T, Petsas T and Dougenis D: Increased $\mathrm{Bax} / \mathrm{Bcl}-2$ ratio up-regulates caspase-3 and increases apoptosis in the thymus of patients with myasthenia gravis. In Vivo 21 : 123-132, 2007.

28. Jiang W, Chen Y, Li B and Gao S: DBA-induced caspase-3dependent apoptosis occurs through mitochondrial translocation of cyt-c in the rat hippocampus. Mol Biosyst 13: 1863-1873, 2017.

29. Zhang Y, Yu W, Jiang X, Lv K, Sun S and Zhang F: Analysis of the cytotoxicity of differentially sized titanium dioxide nanoparticles in murine MC3T3-E1 preosteoblasts. J Mater Sci Mater Med 22: 1933-1945, 2011

30. Kaiser JP, Wick P, Manser P, Spohn P and Bruinink A: Single walled carbon nanotubes (SWCNT) affect cell physiology and cell architecture. J Mater Sci Mater Med 19: 1523-1537, 2008.

31. Xu Z, Zhang YL, Song C, Wu LL and Gao HW: Interactions of hydroxyapatite with proteins and its toxicological effect to zebrafish embryos development. PLoS One 7: e32818, 2012.

32. Delfino RJ, Sioutas C and Malik S: Potential role of ultrafine particles in associations between airborne particle mass and cardiovascular health. Environ Health Perspect 113: 934-946, 2005.

33. Du Z, Zhao D, Jing L, Cui G, Jin M, Li Y, Liu X, Liu Y, Du H, Guo C, et al: Cardiovascular toxicity of different sizes amorphous silica nanoparticles in rats after intratracheal instillation. Cardiovasc Toxicol 13: 194-207, 2013.

34. Bai R, Zhang L, Liu Y, Meng L, Wang L, Wu Y, Li W, Ge C, Le Guyader L and Chen C: Pulmonary responses to printer toner particles in mice after intratracheal instillation. Toxicol Lett 199: 288-300, 2010

35. Sweet MJ, Chessher A and Singleton I: Chapter five-review: Metal-based nanoparticles; size, function, and areas for advancement in applied microbiology. Adv Appl Microbiol 80: 113-142, 2012.

36. Böhme U and Scheler U: Hydrodynamic size and charge of polyelectrolyte complexes. J Phys Chem B 111: 8348-8350, 2007.

37. Oberdörster G, Oberdörster $E$ and Oberdörster J: Nanotoxicology: An emerging discipline evolving from studies of ultrafine particles. Environ Health Perspect 113: 823-839, 2005.

38. Chen Z, Meng H, Xing G, Yuan H, Zhao F, Liu R, Chang X, Gao X, Wang T, Jia G, et al: Age-related differences in pulmonary and cardiovascular responses to $\mathrm{SiO} 2$ nanoparticle inhalation: Nanotoxicity has susceptible population. Environ Sci Technol 42: 8985-8992, 2008

39. Morris AS, Adamcakova-Dodd A, Lehman SE, Wongrakpanich A, Thorne PS, Larsen SC and Salem AK: Amine modification of nonporous silica nanoparticles reduces inflammatory response following intratracheal instillation in murine lungs. Toxicol Lett 241: 207-215, 2016.

40. Kim JH, Kim CS, Ignacio RM, Kim DH, Sajo ME, Maeng EH, Qi XF, Park SE, Kim YR, Kim MK, et al: Immunotoxicity of silicon dioxide nanoparticles with different sizes and electrostatic charge. Int J Nanomedicine 9 (Suppl 2): 183-193, 2014.

41. Aravamudan B, Thompson M, Sieck GC, Vassallo R, Pabelick CM and Prakash YS: Functional effects of cigarette smoke-induced changes in airway smooth muscle mitochondrial morphology. J Cell Physiol 232: 1053-1068, 2016.

42. Li J, Lee B and Lee AS: Endoplasmic reticulum stress-induced apoptosis: Multiple pathways and activation of p53-up-regulated modulator of apoptosis (PUMA) and NOXA by p53. J Biol Chem 281: 7260-7270, 2006.

43. Satoh M, Matter CM, Ogita H, Takeshita K, Wang CY, Dorn GW II and Liao JK: Inhibition of apoptosis-regulated signaling kinase- 1 and prevention of congestive heart failure by estrogen. Circulation 115: 3197-3204, 2007.

44. Murphy AN: Potential mechanisms of mitochondrial cytochrome-C release during apoptosis. Drug Dev Res 46: 18-25, 1999.

45. Wang Z, Lin D, Zhang L, Liu W, Tan H and Ma J: Penehyclidine hydrochloride prevents anoxia/reoxygenation injury and induces H9c2 cardiomyocyte apoptosis via a mitochondrial pathway. Eur J Pharmacol 797: 115-123, 2017. 
46. Del Principe MI, Dal Bo M, Bittolo T, Buccisano F, Rossi FM, Zucchetto A, Rossi D, Bomben R, Maurillo L, Cefalo M, et al: Clinical significance of bax/bcl-2 ratio in chronic lymphocytic leukemia. Haematologica 101: 77-85, 2016.

47. Marks N, Berg MJ, Guidotti A and Saito M: Activation of caspase-3 and apoptosis in cerebellar granule cells. J Neurosci Res 52: 334-341, 1998.

48. Julien O and Wells JA: Caspases and their substrates. Cell Death Differ 24: 1380-1389, 2017.

49. Shafagh M, Rahmani $\mathrm{F}$ and Delirezh N: $\mathrm{CuO}$ nanoparticles induce cytotoxicity and apoptosis in human K562 cancer cell line via mitochondrial pathway, through reactive oxygen species and P53. Iran J Basic Med Sci 18: 993-1000, 2015.

50. Al-Qubaisi MS, Rasedee A, Flaifel MH, Ahmad SH, Hussein-Al-Ali S, Hussein MZ, Zainal Z, Alhassan FH, Taufiq-Yap YH, Eid EE, et al: Induction of apoptosis in cancer cells by NiZn ferrite nanoparticles through mitochondrial cytochrome C release. Int J Nanomedicine 8: 4115-4129, 2013.
51. Sharma V, Anderson D and Dhawan A: Zinc oxide nanoparticles induce oxidative DNA damage and ROS-triggered mitochondria mediated apoptosis in human liver cells (HepG2). Apoptosis 17: 852-870, 2012.

52. Sun L, Li Y, Liu X, Jin M, Zhang L, Du Z, Guo C, Huang P and Sun Z: Cytotoxicity and mitochondrial damage caused by silica nanoparticles. Toxicol In Vitro 25: 1619-1629, 2011.

This work is licensed under a Creative Commons Attribution-NonCommercial-NoDerivatives 4.0 International (CC BY-NC-ND 4.0) License. 